\title{
MODELLING AND PREDICTION OF THE MECHANICAL PROPERTIES OF TIG WELDED JOINT FOR AISI 4130 LOW CARBON STEEL PLATES USING
} ARTIFICIAL NEURAL NETWORK (ANN) APPROACH

\author{
I. Owunna ${ }^{1}$ and A. E.Ikpe ${ }^{2, *}$ \\ 1, 2, Dept of MeChanical Engineering, University of Benin, P.M.B. 1154, Benin, Edo STATE, NIGERIA \\ E-mail addresses: ${ }^{1}$ ikechukwu.owunna@uniben.edu, ${ }^{2}$ ikpeaniekan@gmail.com
}

\begin{abstract}
The mechanical properties (Ultimate Tensile Strength (UTS), modulus of elasticity (E), elongation and strain (e)) for twenty samples of AISI 4130 Low carbon steel plate were studied in this paper. Statistical design of experiment (DOE) using the central composite design method (CCD) was employed in Design Expert 7.01 software to generate DOE for twenty (20) experimental runs as input variables (current, voltage and gas flowrate) which were used in predicting and optimizing the output parameters (maximum UTS and maximum modulus of elasticity with corresponding elongation and strain). One out of the 20 welding runs was found to be optimum using the Artificial Neural Network (ANN) optimization approach. The same twenty (20) predicted variables were subjected to TIG welding experimentation which showed close proximity between the predicted and experimental values. Optimized ANN predicted output parameters were UTS of 421 $\mathrm{MPa}$, modulus of elasticity of $793 \mathrm{MPa}$, strain of 0.61 and elongation of $61 \%$ while experimental values using the optimized input variables produced output parameters of 427 MPa for UTS of 421 $\mathrm{MPa}, 806 \mathrm{MPa}$ for modulus of elasticity, strain of 0.62 and $62 \%$ elongation. Visuals of the weldment obtained from Scanning Electron Microscopy with Energy Dispersive Spectroscopy (SEM/EDS) revealed a uniformly distributed grain sizes in the weldment primarily composing of iron (Fe), chromium (Cr), molybdenum (Mo), and nickel (Ni). To save time, energy and resources required for welding experimentation processes, conventional software such as ANN can be used to obtain accurate results.
\end{abstract}

Keywords: Modelling, Prediction, Low carbon steel, TIG welding, Welding variables.

\section{INTRODUCTION}

Tungsten Inert Gas (TIG) also known as Gas Tungsten Arc Welding (GTAW) is a welding method that is commonly used for joining thin and dissimilar materials, and are more suitably for welding metals and their alloys [1]. TIG welding process involves the use of non-consumable tungsten electrodes such as EWTh-2，EWZR-1，EWLa-2， EWLa-1.5， EWLa-1, EWCe-2, EWP, to produce an arc and a filler wire to join the desired metals together while simultaneously shielding the welding process with inert gas such as helium or argon to protect the molten weld pool from atmospheric contaminants [2]. According to Kamble and Rao [3], heat distribution around the weldment usually alters the chemical and mechanical properties which depends upon the chemical composition of the bead and its geometry. The microstructures and mechanical properties obtained from welding steel materials depend on certain properties such as percentage of carbon and other elements such as chromium, nickel, molybdenum, sulphur, etc. For example, low carbon steel materials with less than $0.25 \%$ carbon exhibits good welding characteristics with minor defects [4].

Experiment carried out by Lin et al. [5] on mechanical properties of TIG weldment of Boron FeTi-B alloy after post-weld heat treatment revealed that the weldment had slightly higher yield strength and lower tensile strength compared to those of the base metal. Huang et al. [6] used GTAW multi-pass

\footnotetext{
* Corresponding author, tel: +234-902-477-3812
} 
welding method to weld two dissimilar metals (S355JR carbon steel and 316L stainless steel plates), and consequently investigated the microstructural characteristics, mechanical properties and corrosion behaviour of the welded dissimilar joint. The results obtained revealed that the microstructure of the weldment was a combination of austenite and vermiform $\delta$-ferrite. There was a decarburisation layer on the interface of S355JR whereas, the damaged phase $\sigma$ and $\mathrm{M}_{23} \mathrm{C}_{6}$ (chromium carbide) were not observed in the $\mathrm{X}$-ray diffraction. In addition, the corrosion resistance of the weldment decreased when compared to $316 \mathrm{~L}$ base material.

Hussain et al. [7] studied the influence of TIG welding speed on the tensile strength of aluminum AA6351alloy and obtained maximum tensile strength of $230 \mathrm{MPa}$ at welding speed of $0.6 \mathrm{~cm} / \mathrm{sec}$, with a conclusion that the base metal was stronger than the welded joint. However in the same TIG welding experimentation, it was also observed that tensile strength tends to increase with lower welding speed. Singh et al. [8] evaluated the TIG welding parametric influence on Tensile strength of 5083 aluminum alloy, and found that tensile strength and welding speed increased pari passu, but later decreased by further increase in welding speed after attaining a maximum tensile strength of $129 \mathrm{MPa}$ at welding current of 240 A, gas flow rate of $7 \mathrm{~L} / \mathrm{min}$ and welding speed of 98 $\mathrm{mm} / \mathrm{min}$. Kurt and Samur [9] investigated the mechanical properties of 304 stainless steel weldment after TIG welding application and observed an UTS of $1800 \mathrm{MPa}$, yield strength of $75 \mathrm{MPa}$, percentage elongation of $25 \%$, with crack initiation in the Heat Affected Zone (HAZ). Proper attention is required while selecting welding variable input process parameters, as improper welding variables can produce poor welds with inadequate mechanical properties such as tensile strength, toughness, hardness etc, [10]. One way of selecting proper welding variables is by optimization of the process parameters, and conventional numerical techniques includes statistical design of experiment such as the use of Response Surface Methodology (RSM), Artificial Neural Network (ANN), Finite Element Method (FEM) and Taguchi method etc. According to Benyounis and Olabi [11], optimization of welding parameters is essential to obtaining good weldment with the required bead geometry and weld quality. Kumar and Vijay [12] employed Taguchi approach of orthogonal array using analysis of variance (ANOVA) to determine the influence of process parameter (current, voltage and gas flow rate) on the mechanical properties of TIG welding joint of austenitic stainless steel (AISI 316) and mild steel. The result indicated that these parameters influenced the tensile strength and hardness of the welded joint if they are not optimised to obtain optimum range of values. This study is focused on modelling and prediction of the mechanical properties of AISI 4130 low carbon steel plate using Artificial Neural Network (ANN) Approach to generate/predict Design of Experiment DOE) for twenty (20) welding runs as well as optimization to determine the most suitable sets of welding parameters followed by TIG Welding Experimentation using the DOE and microstructural analysis of the weldment achieved by application of the optimized parameter.

\section{MATERIALS AND METHOD}

As shown in Table 1, statistical design of experiment (DOE) using the central composite design method (CCD) was employed in Design Expert 7.01 software to generate DOE for twenty (20) experimental runs as input variables (current, voltage and gas flowrate) for TIG welding experimentation and ANN was used in modelling, predicting and optimizing the welding output variables.

Table 1: Design of experiment for TIG Input Variables

\begin{tabular}{cccc}
\hline $\begin{array}{c}\text { Weld } \\
\text { Runs }\end{array}$ & $\begin{array}{c}\text { Current } \\
(\mathrm{A})\end{array}$ & $\begin{array}{c}\text { Voltage } \\
(\mathrm{V})\end{array}$ & $\begin{array}{c}\text { Gas Flow Rate } \\
(\text { L/min })\end{array}$ \\
\hline 1 & 155 & 22 & 15.5 \\
2 & 155 & 22 & 15.5 \\
3 & 155 & 22 & 15.5 \\
4 & 155 & 22 & 15.5 \\
5 & 155 & 22 & 15.5 \\
6 & 155 & 22 & 15.5 \\
7 & 155 & 27 & 15.5 \\
8 & 96.1 & 22 & 15.5 \\
9 & 155 & 22 & 11.3 \\
10 & 155 & 16.9 & 15.5 \\
11 & 213.8 & 22 & 15.5 \\
12 & 155 & 22 & 19.7 \\
13 & 120 & 19 & 18 \\
14 & 190 & 19 & 13 \\
15 & 190 & 25 & 13 \\
16 & 120 & 25 & 18 \\
17 & 190 & 25 & 18 \\
18 & 120 & 19 & 13 \\
19 & 120 & 25 & 13 \\
20 & 190 & 19 & 18 \\
\hline
\end{tabular}

Materials and specifications used for the welding experimentation are presented in Table 2 while the 
chemical and mechanical properties of AISI 4130 low carbon steel are presented in Table 3. Figure 1 shows the breaking point of each sample after the tensile test.

After welding, each of the welded samples were subjected to Scanning Electron Microscopy with
Energy Dispersive Spectroscopy (SEM/EDS) to check the mechanical properties and characterization of the weldment. The above input variables were employed in the TIG welding process to join the workpiece together before being subjected to tensile test.

Table 2: Materials and Specifications used for the Welding Experimentation

\begin{tabular}{lll}
\hline S/N & Material Specification & Welding Specification \\
\hline 1 & Welding Type & Tungsten Inert Gas (TIG) \\
2 & Material & AISI 4130 Low Carbon Steel Plate \\
7 & Material Thickness & $7 \mathrm{~mm}$ \\
8 & Filler Material & ER $70 \mathrm{~S}-6$ \\
9 & Joint Type & Butt Joint (V-groove) \\
10 & Joint Preparation & Abrasive Clean (Sand paper)/Acetone Wipe \\
11 & Joint Gap & $2 \mathrm{~mm}$ \\
12 & Welding Current & D.C.E.N (Direct Current Electrode Negative) \\
13 & Pulse Width & 0.8 Seconds \\
14 & Filler Rod Angle & $15^{\circ}$ \\
15 & Welding Torch Angle & $45^{\circ}$ \\
16 & Fixed Frequency & $60 \mathrm{~Hz}$ \\
17 & Torch Type & Pro-torch (TIG Torch) \\
18 & Tungsten Type & $2 \%$ thoriated \\
19 & Tungsten Size & $3 / 1326^{\prime \prime}$ Diameter $\times 25.4$ mm \\
20 & Torch Gas & Argon (100\%) \\
21 & Heat Input Ratio & $10.75 \mathrm{KJ} /$ min \\
22 & Weight of Filler Rod & $78.5 \mathrm{Kg} / \mathrm{m}^{2}$ \\
23 & Welding machine & Dynasty 210 DX \\
24 & Clamp type & G-clamp for clamping the work pieces \\
25 & Vertical milling machine & For milling the V-groove angle \\
26 & Tensile machine & Instron \\
\hline
\end{tabular}

Table 3: Chemical and Mechanical Properties for AISI 4130 Low Carbon Steel

\begin{tabular}{llll}
\hline \multicolumn{2}{c}{ Chemical Composition } & & \multicolumn{2}{c}{ Mechanical Composition } \\
\hline Element & Content \% & Properties & Values (Metric Unit) \\
\hline Iron (Fe) & $97.0-98.2$ & Ultimate Tensile Strength & $560 \mathrm{MPa}$ \\
Chromium (Cr) & $0.8-1.1$ & Yield Strength & $460 \mathrm{MPa}$ \\
Manganese (Mn) & $0.4-0.6$ & Modulus of Elasticity & $190-210 \mathrm{GPa}$ \\
Nickel (ni) & $0.16-0.25$ & Poison Ratio & $0.27-0.30$ \\
Molybdenum (MO) & $0.15-0.25$ & Brinell Hardness & 217 \\
Carbon (C) & $0.280-0.330$ & Shear Modulus & $80 \mathrm{MPa}$ \\
Silicon & $0.15-0.30$ & Bulk Modulus & $140 \mathrm{MPa}$ \\
Sulfur (S) & 0.040 & Thermal Conductivity $\left(100^{\circ}\right)$ & $42.7 \mathrm{~W} / \mathrm{mK}$ \\
Phosphorous (P) & 0.035 & Machinability & 70 \\
\hline
\end{tabular}

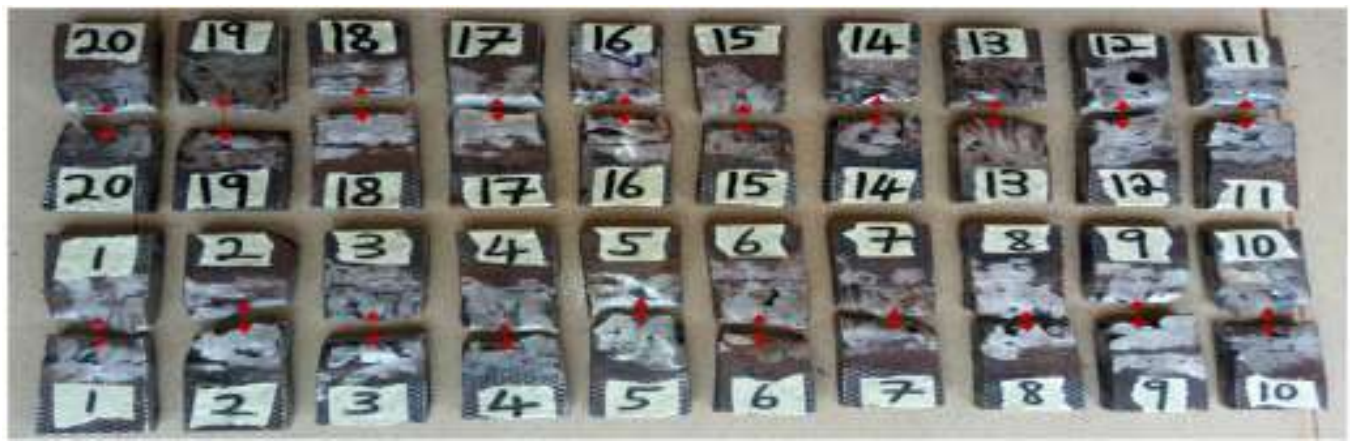

Figure 1: Samples Subjected Tensile test showing the Breaking Point 
Instron tensile test machine was used to achieve the tensile test and corresponding mechanical properties which included the ultimate tensile strength, modulus of elasticity, percentage elongation and strain. All the twenty (20) specimens subjected to variable loading (applied forces) intervals were $7 \mathrm{~mm}$ thickness with $110 \times 35 \mathrm{~mm}$ length and width.

\section{MODELLING AND PREDICTION USING ANN}

To predict the response variables beyond the scope of experimentation, predictive model such as artificial neural network (ANN) was employed. Sixty (60) experimental data generated by replicating the design matrix from the CCD was used for the neural network modelling. The experimental data were first normalized to avoid the problem of weight variation that may consequently results in overtraining which is a major limitation in neural network modelling.

The aim of normalization was to reduce the weight of the input and output variables to between 0 and 1 so as to allow for effective network training and accurate modelling and prediction. To train a neural network for predicting the UTS, Modulus of Elasticity (E), percentage elongation and strain a feed forward back propagation algorithm was used. The input layer of the network uses the hyparbolic targent (tansigmoid) transfer function to calculate the layer output from the network input while the output layer uses the linear (purelin) transfer function. The number of hidden neuron was set at 10 neurons per layer and the network performance was monitored using the mean square error of regression (MSEREG). A learning rate of 0.01 , momentum coefficient of 0.1 , target error of 0.01 , analysis update interval of 500 and a maximum training cycle of 1000 epochs was used. The network generation process divided the input data into training data sets, validation and testing. In this study, $60 \%$ of the data was employed to perform the network training, $25 \%$ for validating the network while the remaining $15 \%$ was used to test the performance of the network. Trainlm is a network training function that updates weight and bias values according to Levenberg-Marquardt optimization. Trainlm is often the fastest back propagation algorithm in the toolbox, and is highly recommended as a first-choice supervised algorithm, since it does require more memory than other algorithms. Using these parameters, an optimum neural network architecture was generated as presented in Figure 2. The same network architure was generated to predict the four (4) output variables, namely; UTS, Modulus of Elasticity (E), elongation and strain since the same input parameters were used.

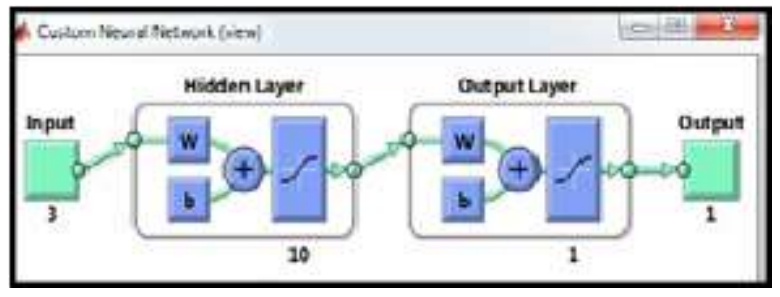

Figure 2: Artificial neural network architecture

\subsection{Prediction of UTS using ANN}

The network training diagram was generated for the prediction of UTS using back propagation neural network. From the network training sequence, it was observed that the network performance was significantly good with a performace error of 3.81e07 which is far lesser than the set target error of 0.01 . The maximum number of iteration needed for the network to reach this performance was observed to be 14 iterations which is also lesser than the initial 1000 epochs. The gradient function was calculated to be 0.000388 with a training gain $(\mathrm{Mu})$ of $1.00 \mathrm{e}-12$. Validation check of six (6) was recorded which is expected since the issue of wieght biased had been addressed via normalization of the raw data. A performance evaluation plot which shows the progress of training, validation and testing is presented in Figure 3.

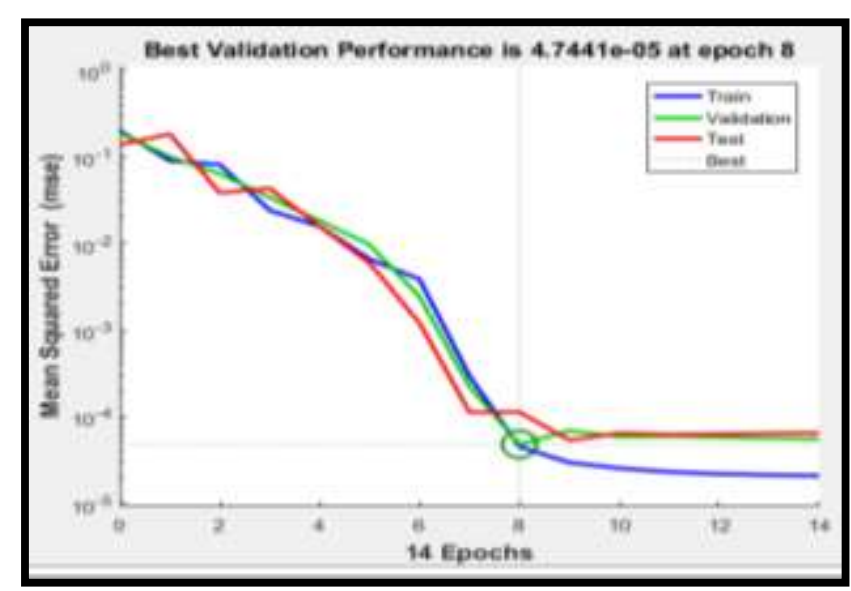

Figure 3: Performance curve of trained network for predicting UTS

From the performance plot of Figure 3, no evidence of over fitting was observed. In addition similar trend 
was observed in the behavior of the training, validation and testing curve which is expected since the raw data were normalized before use. Lower mean square error is a fundamental criteria used to determine the training accuracy of a network. An error value of $4.7441 \mathrm{e}-05$ at epoch 8 is an evidence of a network with strong capacity to predict the weldment UTS. The training state, which shows the gradient function, the training gain $(\mathrm{Mu})$ and the validation check, is presented in Figure 4.

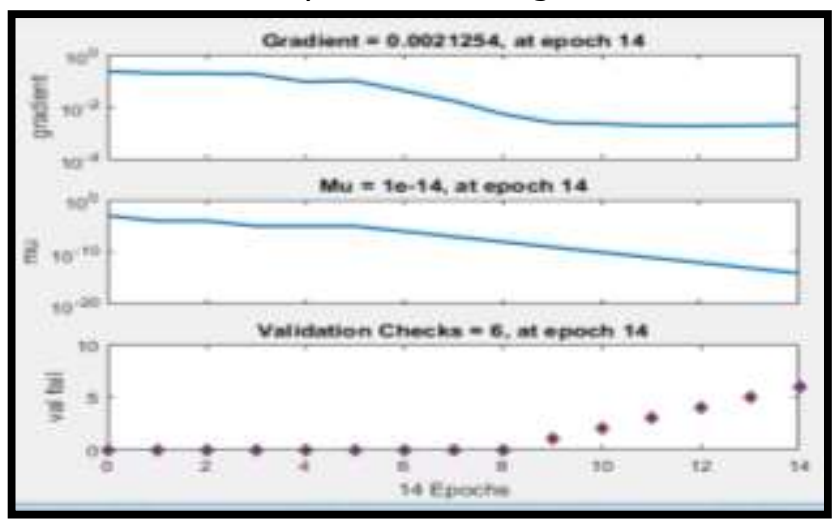

Figure 4: Neural network training state for predicting UTS of weldment

Back propagation is a method used in artificial neural networks to calculate the error contribution of each neuron after a batch of data training. Technically, the neural network calculates the gradient of the loss function to explain the error contributions of each of the selected neurons. Lower error is better. Computed gradient value of 0.0021254 as observed in Figure 4, indicated that the error contributions of each selected neurons is very minimal. Momentum gain $\mathrm{(Mu})$ is the control parameter for the algorithm used to train the neural network. It is the training gains and its value must be less than unity. Momentum gain of $1.0 \mathrm{e}-14$ shows a network with high capacity to predict the UTS. The regression plot which shows the correlation between the input variables (current, voltage and gas flow rate) and the target variable (UTS of weldment) coupled with the progress of training, validation and testing is presented in Figure 5.

Based on the computed values of the correlation coefficient (R) as observed in Figure 5, it was concluded that the network has been accurately trained and can be employed to predict the weldment UTS. To test the reliability of the trained network, the network was thereafter employed to predict its own values of UTS using the same set of input parameters (current, voltage and gas flow rate) generated from the central composite design.

\section{RESULTS AND DISCUSSION}

The aforementioned ANN procedures for UTS were adopted to obtain the ANN predicted values for modulus of elasticity, ANN predicted strain values and ANN predicted percentage elongation respectively. The images were taken at approximately four millimetres $(\sim 4 \mathrm{~mm})$ of the welded joint where high changes in the microstructure of the material are produced
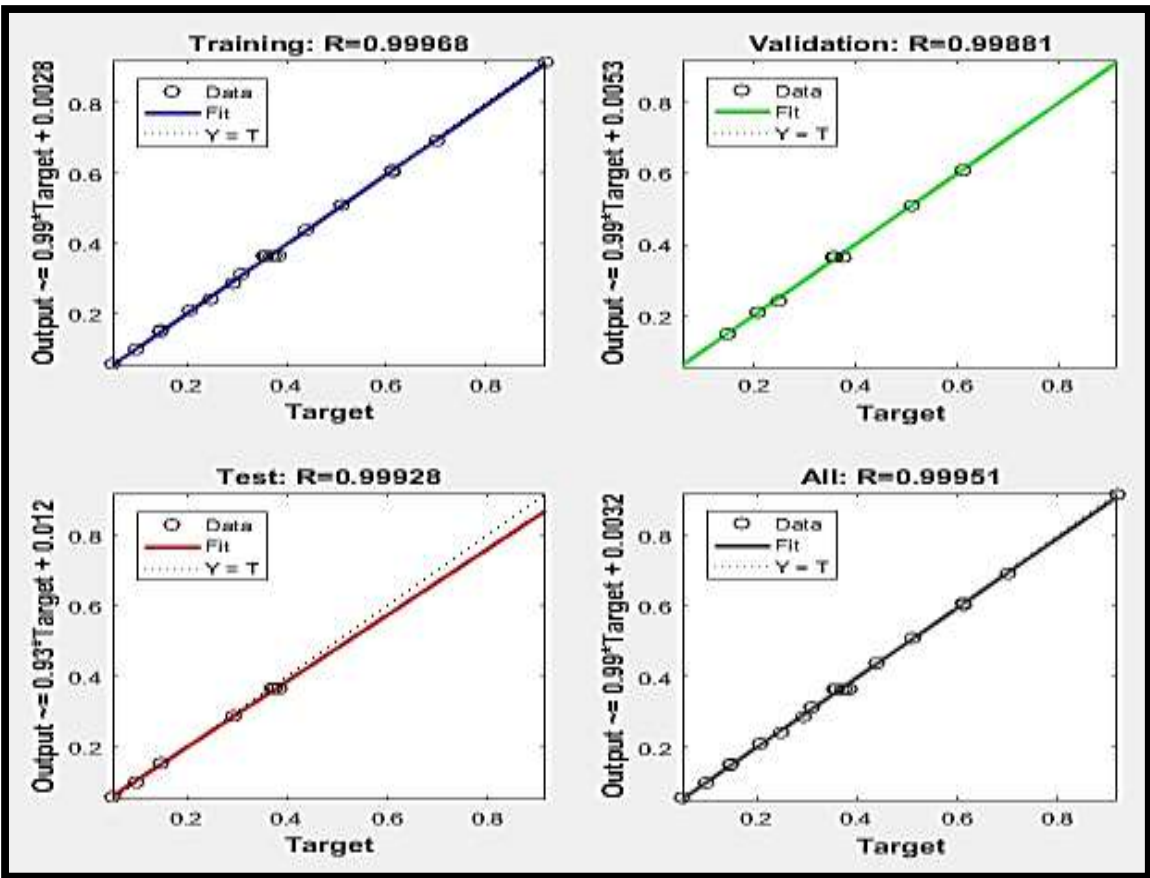

Figure 5: Regression Plot Showing the Progress of Training, Validation and Testing 


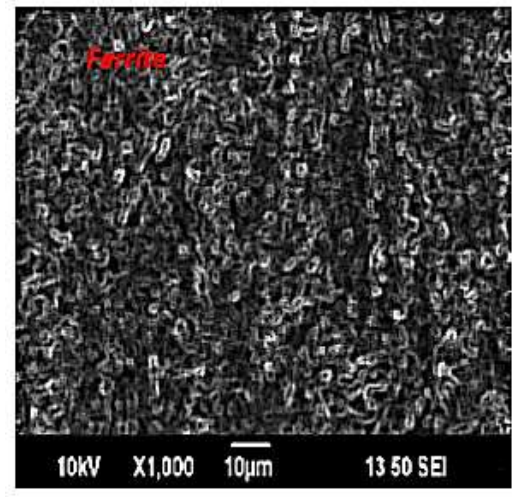

(a). Before Welding

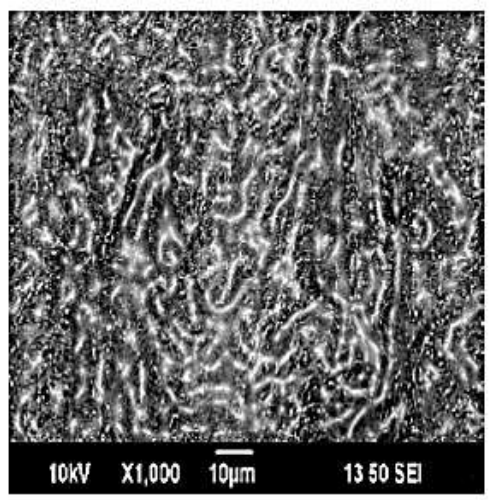

(b). Molten Weld Pool

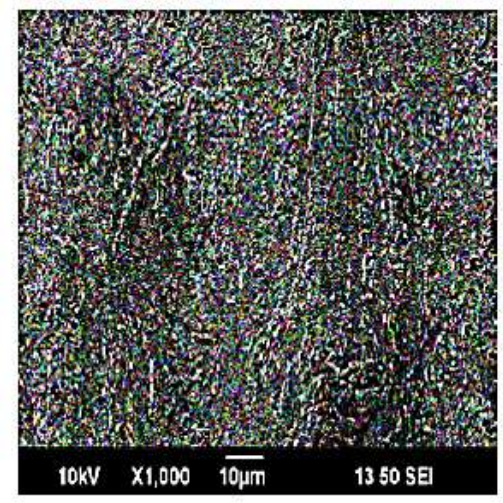

(c). Cooled at Ambient Temperature

Figure 6: SEM images of the samples taken at $\sim 4 \mathrm{~mm}$ of the welded joint

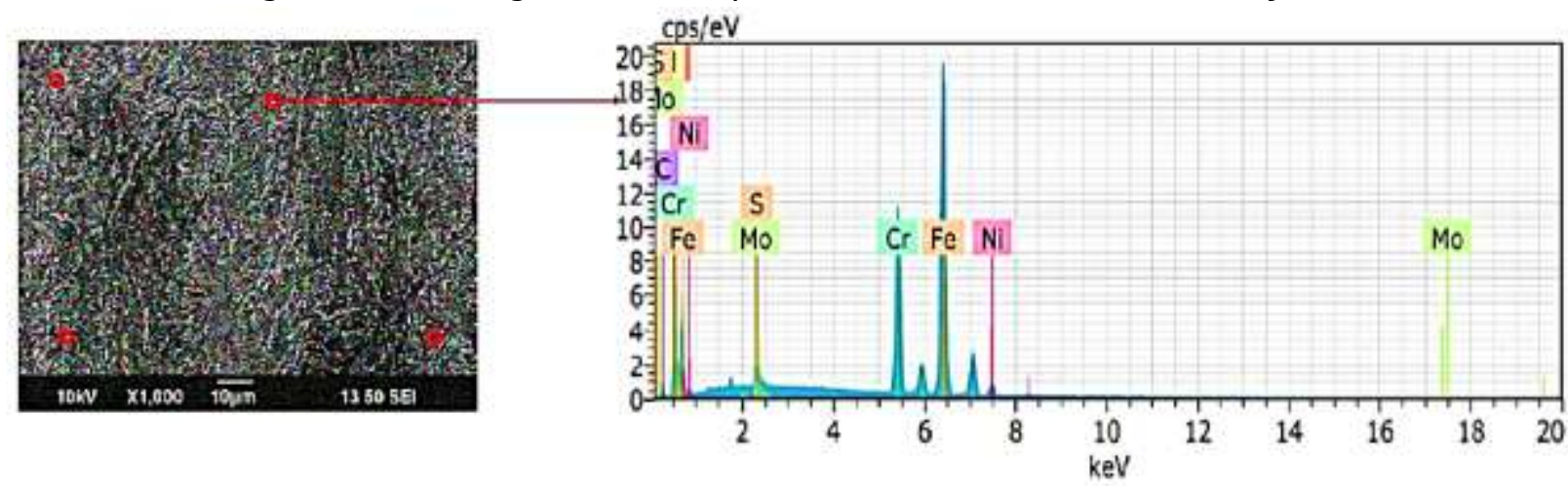

Figure 7: EDS study of the welded samples

The sample in Figure 6a shows a typical low carbon steel microstructure where the grain sizes constituting mainly of ferrite can be observed whereas Figure $6 b$ and $c$ represents a typical low carbon steel microstructure where the grain particles are barely noticeable across the entire weldment.

It can be observed on the low carbon steel micro structure in Figure $6 \mathrm{c}$ that the grain particles are almost uniformly distributed across the weldment after cooling which took less time due to the elemental compositions that constitutes the weldment. Ferrite number is a standard value for designating the ferrite content within an austenitic stainless steel. The percentage of ferrite in a weldment is due to the amount of oxide addition during welding $[13,14]$. The elemental composition of the weldment cooled at ambient temperature was observed through SEM/EDS. The typical EDS study is shown in Figure 7.

The TIG welding process with optimised parameters exhibited high energy density of heat source thereby resulting in moderate heat input and rapid cooling cycle, causing low ferrite. As a result of different elemental partitioning, each phase possessed a different Pitting Resistance equivalent Number
(PREN). However, due to rapid cooling rates, the partitioning ratio tends to unite for $\mathrm{Cr}, \mathrm{Mo}$, and $\mathrm{Ni}$ as shown in Figure 7. In case of nitrogen, it was assumed that ferrite attained its saturation level to $0.05 \%$. Therefore, the nitrogen content in the austenite phase can be determined based on the content of nitrogen in the entire material and in the phase volume fraction. In cases where the weldment of the low carbon steel is exposed to hot air, it oxidizes rapidly to form iron oxide $(\mathrm{FeO})$ which degrades the exposed part by making it susceptible to corrosion, but some element like chromium which has a large energy of oxidation dissolved in the steel forms thin film layer of its own oxide $\left(\mathrm{Cr}_{2} \mathrm{O}_{3}\right)$ on the surface of the steel to partially protect it from any oxidizing effect [15]. In TIG welding application, the said oxidation is called surface contamination and can be prevented through the use of inert gases such as argon, helium etc. Argon gas was employed as the shielding gas in this investigation to prevent surface contamination of the welding process which can undermines the integrity of weldment, thereby producing poor weld quality. Studies have shown that the application of pure argon or helium as shielding gas can lead to Nitrogen loss [16], of which the addition of Nitrogen to shielding gas can increase the 
rate of partial transformation from ferrite to austenite in the cooling phase after welding, and increase in austenite improves the weld pitting corrosion resistance [17]. Sathiya et al., [18] reported that the use of argon as shielding gas can produce substantial amount of ferrite than with helium shielded metal, but since the use of helium helps maintain a hotter arc, it as well provides a suitable cooling rate for phase transformation from a to $y$ phase for improved impact toughness of the weld. However, protection by alloying has a great deal of advantage over protection by surface coating, as protection by alloying repairs itself when damaged. In other words, if the protected film is abraded during service condition of the steel material, the chromium content immediately oxidises, thereby, compensating for the abraded part. This correlates with a review carried out by Mohammed et al., [14] on the effects of heat input on microstructure, corrosion and mechanical properties of welded Austenitic and Duplex stainless steels. While nickel in most case decrease the case depth of carburized steels, chromium increases it. However in the formation of retained austenite for the case of carburized and hardened steels, chromium is more effective than nickel, whereas, nickel and chromium are suitable element required in the refinement of austenite grain size of carburized steels, but nickel is more effective in austenite grain growth inhibition than chromium. The combined effect of molybdenum and nickel is much more effective than either of these two elements in case depth increase, but undissolved grain particles of molybdenum carbide $\left(\mathrm{MO}_{2} \mathrm{C}\right)$ plays a significant role in austenitic grain size refinement of carburized steels [19], as the presence of nickel enhances the effect of molybdenum in this case. Hardness value was recorded at the weldment, HAZ and area after the HAZ. Due to the heating effects on the weldment, value of hardness at the welded joint was $118 \mathrm{BN}$ and in HAZ (Heat Affected Zone) it was $114 \mathrm{BN}$ and away from the HAZ was decreasing up to $98 \mathrm{BN}$. The weldment was found to contain nickel, chromium, manganese, carbon, iron etc. from which maximum case hardness can be obtained through oil quenching and desired mechanical property like tensile strength of up to $1360 \mathrm{MPa}$ with adequate toughness through proper selection of alloying elements.

As shown in Figures 8 and 9, both the ANN predicted TIG welding values and TIG welding experimental carried out under input welding variables of $120 \mathrm{~A}$ current, $19 \mathrm{~V}$ voltage and $13 \mathrm{~L} / \mathrm{min}$ gas flowrate correlated with each other as presented in the experimental run serial number 18 in Table 4 and 5.

Table 4: Results of Welding Output Parameters from ANN Prediction

\begin{tabular}{ccccccc}
\hline $\begin{array}{c}\text { ANN } \\
\text { (Runs) }\end{array}$ & $\begin{array}{c}\text { Force } \\
(\mathrm{N})\end{array}$ & $\begin{array}{c}\text { Area } \\
\left(\mathrm{mm}^{2}\right)\end{array}$ & $\begin{array}{c}\text { ANN Predicted } \\
\text { Ultimate Tensile } \\
\text { Strength UTS (MPa) }\end{array}$ & $\begin{array}{c}\text { ANN Predicted } \\
\text { Modulus of } \\
\text { Elasticity E (MPa) }\end{array}$ & $\begin{array}{c}\text { ANN } \\
\text { Predicted } \\
\text { Strain e }\end{array}$ & $\begin{array}{c}\text { ANN Predicted } \\
\% \text { Elongation } \\
(\%)\end{array}$ \\
\hline 1 & 121,000 & 340 & 342 & 663 & 0.51 & 51 \\
2 & 132,000 & 333 & 380 & 570 & 0.66 & 66 \\
3 & 114,500 & 326.8 & 342 & 617 & 0.54 & 54 \\
4 & 62,500 & 310.6 & 186 & 674 & 0.28 & 28 \\
5 & 46,000 & 318.2 & 129 & 520 & 0.25 & 25 \\
6 & 51,000 & 329.8 & 142 & 544 & 0.27 & 27 \\
7 & 81,000 & 324.9 & 236 & 682 & 0.35 & 35 \\
8 & 78,000 & 315.2 & 235 & 736 & 0.31 & 31 \\
9 & 85,000 & 289.8 & 280 & 783 & 0.36 & 36 \\
10 & 94,000 & 328.3 & 275 & 780 & 0.34 & 34 \\
11 & 115,500 & 329.8 & 340 & 661 & 0.49 & 49 \\
12 & 132,500 & 335 & 383 & 616 & 0.61 & 61 \\
13 & 109,000 & 323 & 325 & 618 & 0.53 & 53 \\
14 & 104,500 & 329.8 & 305 & 692 & 0.42 & 42 \\
15 & 127,500 & 313.3 & 390 & 689 & 0.57 & 57 \\
16 & 126,500 & 320 & 382 & 633 & 0.6 & 60 \\
17 & 105,000 & 334 & 302 & 610 & 0.48 & 48 \\
18 & 212,000 & 326.8 & 421 & 793 & 0.61 & 61 \\
19 & 137,000 & 320.1 & 362 & 684 & 0.54 & 54 \\
20 & 123,000 & 323 & 370 & 738 & 0.4 & 40 \\
\hline
\end{tabular}


Table 5: Results of Output Parameters from Welding Experimentation

\begin{tabular}{lllcccc}
\hline $\begin{array}{c}\text { Experimental } \\
\text { Runs }\end{array}$ & $\begin{array}{c}\text { Force } \\
(\mathrm{N})\end{array}$ & $\begin{array}{c}\text { Area } \\
\left(\mathrm{mm}^{2}\right)\end{array}$ & $\begin{array}{c}\text { Experimental } \\
\text { Ultimate Tensile } \\
\text { Strength } \\
\text { UTS (MPa) }\end{array}$ & $\begin{array}{c}\text { Experimental } \\
\text { Modulus of } \\
\text { Elasticity E } \\
(\mathrm{MPa})\end{array}$ & $\begin{array}{c}\text { Experimental } \\
\text { Strain }(\mathrm{e})\end{array}$ & $\begin{array}{c}\text { Experimental } \\
\text { Elongation } \\
(\%)\end{array}$ \\
\hline 1 & 121,000 & 340 & 355.8 & 671.4 & 0.53 & 53 \\
2 & 132,000 & 333 & 396.4 & 591.6 & 0.67 & 67 \\
3 & 114,500 & 326.8 & 350.2 & 625.4 & 0.56 & 56 \\
4 & 62,500 & 310.6 & 201.1 & 693.7 & 0.29 & 29 \\
5 & 46,000 & 318.2 & 144.5 & 535.3 & 0.27 & 27 \\
6 & 51,000 & 329.8 & 154.6 & 552.2 & 0.28 & 28 \\
7 & 81,000 & 324.9 & 249.2 & 692.4 & 0.36 & 36 \\
8 & 78,000 & 315.2 & 247.4 & 749.7 & 0.33 & 33 \\
9 & 85,000 & 289.8 & 293.3 & 792.7 & 0.37 & 37 \\
10 & 94,000 & 328.3 & 286.3 & 795.3 & 0.36 & 36 \\
11 & 115,500 & 329.8 & 350.2 & 673.4 & 0.52 & 52 \\
12 & 132,500 & 335 & 395.5 & 637.9 & 0.62 & 62 \\
13 & 109,000 & 323.0 & 337.4 & 624.9 & 0.54 & 54 \\
14 & 104,500 & 329.8 & 316.8 & 704.1 & 0.45 & 45 \\
15 & 127,500 & 313.3 & 406.9 & 701.6 & 0.58 & 58 \\
16 & 126,500 & 320 & 395.3 & 648.0 & 0.61 & 61 \\
17 & 105,000 & 334 & 314.3 & 628.7 & 0.5 & 50 \\
18 & 212,000 & 326.8 & 427.9 & 806.8 & 0.62 & 62 \\
19 & 137,000 & 320.1 & 370.1 & 698.4 & 0.56 & 56 \\
20 & 123,000 & 323 & 380.8 & 732.6 & 0.42 & 42 \\
\hline
\end{tabular}

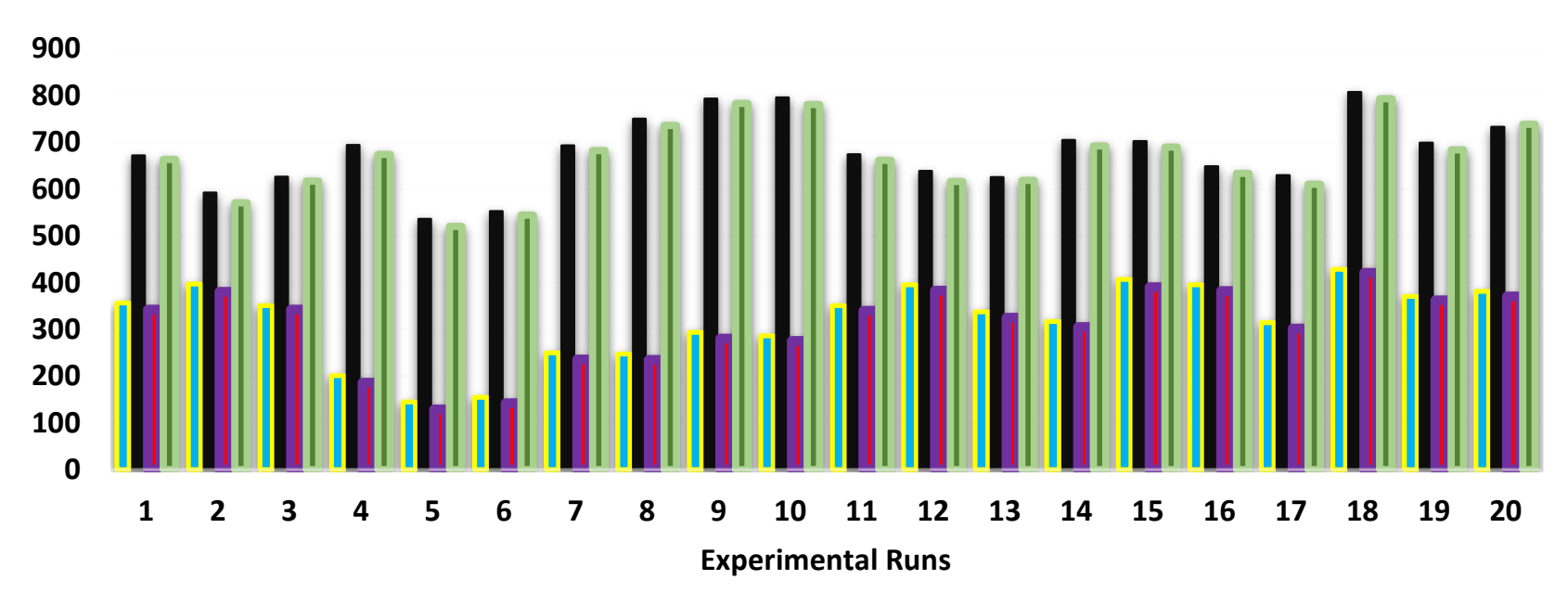

Experimental Ultimate Tensile Strength UTS (Mpa) Experimental Modulus of Elasticity E (Mpa)

ANN Predicted Ultimate Tensile Strength UTS (Mpa) $\quad$ ANN Predicted Modulus of Elasticity E (Mpa)

Figure 8: Graphical Representation of UTS and E from Table 4 and 5 


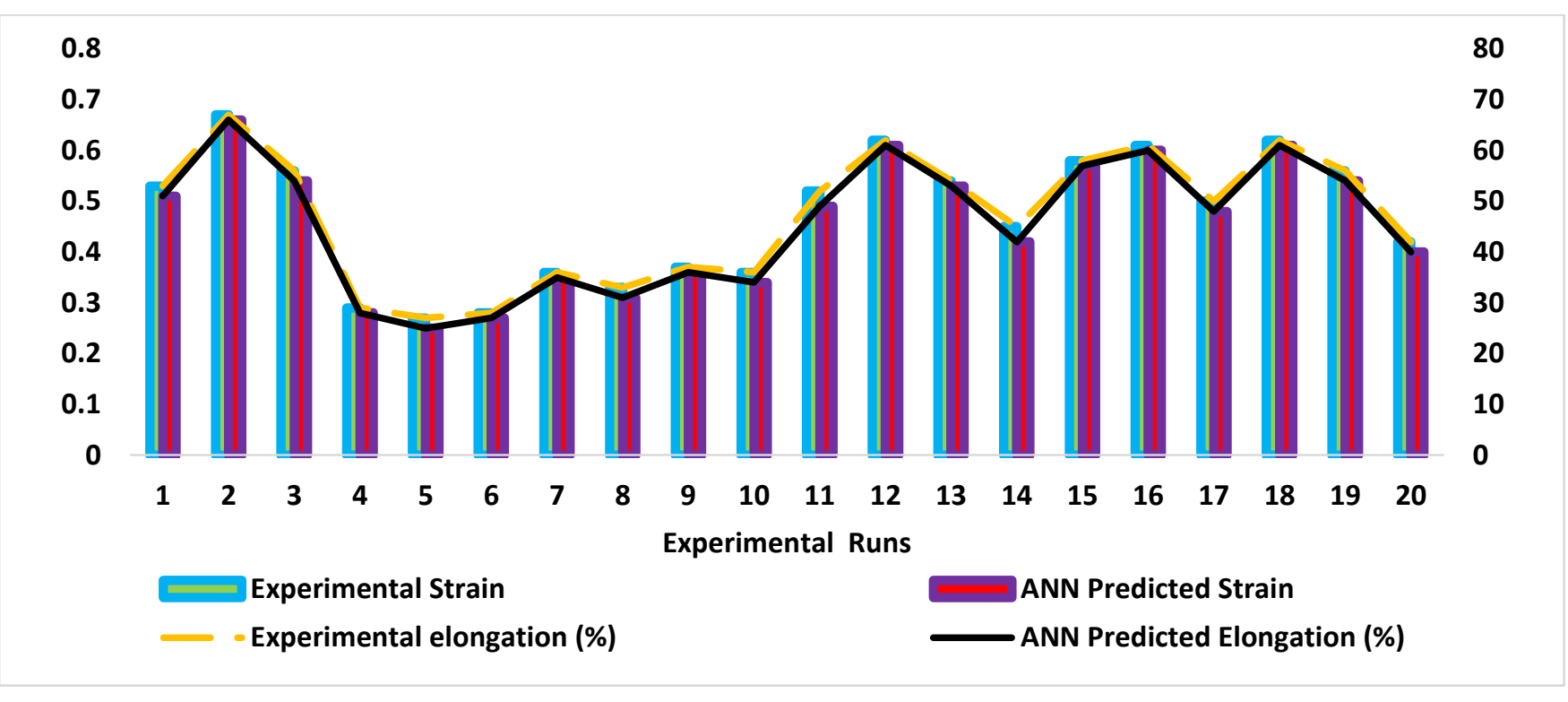

Figure 9: Graphical Representation of Strain and Elongation from Table 4 and 5

\section{CONCLUSION}

Artificial Neural Network modelling methodology for the TIG welding allowed extensive analysis of each input variables for predicting the best possible sets of output parameters, as well as optimizing the output data to obtain optimum values which particularly included maximum UTS which produced $421 \mathrm{MPa}$ and maximum modulus of elasticity which produced 793 MPa. However, the ANN optimised values were validated via TIG welding experimentation using the same input variables, condition and constraints applied in the modelling process and this produced maximum UTS of $427.99 \mathrm{MPa}$ and maximum modulus of elasticity of 806.83 . The slight difference may have been due to unaccounted errors in the experimental process, but much closer proximity was obtained from the modelling (strain of 0.61 and $61 \%$ elongation) and experimentation (strain of 0.62 and $62 \%$ elongation) for strain and elongation using the same input variables and conditions. In spite of the difficulty to acquire the TIG welding materials in order to ensure suitable welding environment, the results obtained from the ANN modelling and prediction is observed to be in agreement with experimental results. It should be noted that accounting for metallurgical transformations of the welded material would present great complexity to the modelling process, as this aspect is not embedded within the operational platform of ANN, as such, this was achieved via SEM/EDS which provided actual representational views of the welded joint metallography. From the standpoint of failure prevention, both the simulations and experiments have demonstrated that the use of optimum welding input variables can have a significant influence on the weld quality in terms of reduction in desired mechanical properties for longevity of welded joints/metal in service condition.

\section{REFERENCES}

[1] Ikpe, A. E., Owunna, I. and Ememobong, I. "Effects of Arc Voltage and Welding Current on the Arc Length of Tungsten Inert Gas Welding (TIG)". International Journal of Engineering Technologies, Vol. 3, Issue 4, pp. 213-221, 2017.

[2] Srirangan, A. K. and Paulraj, S. "Multi-response optimization of process parameters for TIG welding of Incoloy $800 \mathrm{HT}$ by Taguchi grey relational analysis". Engineering Science and Technology, an International Journal, Vol. 19, Issue 2, pp. 811-817, 2016.

[3] Kamble, A. G. and Rao, R. V. "Experimental Investigation on the Effects of Process Parameters of GMAW and Transient Thermal Analysis of AISI321 Steel". Advances in Manufacturing Vol. 1, Issue 4, pp. 362-377, 2013.

[4] Boumerzoug, Z., Derfouf, C., and Baudin, T. "Effect of Welding on Microstructure and Mechanical Properties of an Industrial Low Carbon Steel". Engineering, Vol. 2, Issue 7, pp. 502-506, 2010.

[5] Lin, H., Ying, L. and Binghong, L. J. "Microstructure and Mechanical Properties for TIG Welding Joint of High Boron FE-Ti-B Alloy". 
Rear Metal Materials and Engineering, Vol. 43, Issue 2, pp. 0283-0286, 2014.

[6] Huang, B. S., Yang, J., Lu, D. H. and Bin, W. J. "Study on the Microstructure, Mechanical Properties and Corrosion Behaviour of S355JR/316L Dissimilar Welded Joint Prepared by Gas Tungsten Arc Welding Multi-pass Welding Process". Journal of Science and Technology of Welding and Joining, Vol. 21, Issue 5, 381-388, 2016.

[7] Hussain, A. K., Lateef, A., Javed, M. and Pramesh, T. "Influence of Welding Speed on Tensile Strength of Welded Joint in TIG Welding Process". International Journal of Applied Engineering Research, DINDIGUL, Vol. 1, Issue 3, pp. 518-527, 2010.

[8] Singh, L., Singh, R., Singh, N. K., Singh, D. and Singh, P. "An Evaluation of TIG Welding Parametric Influence on Tensile Strength of 5083 Aluminium Alloy". International Journal of Mechanical and Mechatronic Engineering, Vol. 7, Issue 11, pp. 2326-2329, 2013.

[9] Kurt, H. I. and Samur, R. "Study on Microstructure, Tensile Strength and Hardness 304 Stainless Steel Jointed by TIG Welding". International Journal of Science and Technology, Vol. 2, Issue 2, pp. 163-168, 2013.

[10] Memduh K., Ahmet Y., Mustafa B., and Zarif C. "Effects of Welding Current and Arc Voltage on FCAW Weld Bead Geometry". International Journal of Research in Engineering and Technology, Vol. 4, Issue 9, pp. 23-28, 2015.

[11] Benyounis, K. Y. and Olabi, A. G. "Optimization of Different Welding Processes Using Statistical and Numerical Approaches: A Reference Guide". Advances in Engineering Software, Vol. 39, Issue 6, pp. 483-496, 2008.

[12] Kumar, R. A. and Vijay, M. "Parametric Optimization of TIG Welding on Joint of
Stainless Steel (316) and Mild Steel Using Taguchi Technique". International Research Journal of Engineering and Technology, Vol. 4, Issue 5, pp. 366-370, 2017.

[13] Datta, P. and Upadhyaya, G. "Sintered Duplex Stainless Steels from Premixes of 316L and 434 L Powders" Materials, Chemistry and Physics, Vol. 67, Issue 1-3, 234-242, 2001.

[14] Mohammed, G. R., Ishak, M. Aqida, S. and Abduhadi, H. A. "Effects of Heat Input on Microstructure, Corrosion and Mechanical Characteristics of Welded Austenitic and Duplex Stainless Steels: A Review". Metals, Vol. 7, Issue 39, , pp. 1-18. 2017.

[15] Karlsson, J. "Pitting Corrosion on Stainless Steel with and without Passivation". Lund University, Sweden, pp. 1-31, 2017.

[16] Kah, P. and Martikainen, J. "Influence of Shielding Gases in the Welding of Metals". International Journal of Advanced Manufacturing Technology, Vol. 64, Issue 9-12, pp. 1411-1421, 2012.

[17] Bhatt, R. B., Kamat, H. S., Ghosal, S. K. and $\mathrm{De}, \mathrm{P}$. K. "Influence of Nitrogen in the Shielding Gas on Corrosion Resistance of Duplex Stainless Steel Welds". Journal of Materials Engineering and Performance, Vol. 8, Issue 5, , pp. 591-597. 1999.

[18 Sathiya, P., Aravindan, S., Soundararajan, R. and Noorul, H. A. "Effects of Shielding Gases on Mechanical and Metallurgical Properties of Duplex Stainless-Steel Welds". Journal of Material Science, Vol. 44, Issue 1, pp. 114-121, 2009.

[19] Bepari, M. M. A. "2.3 Carburizing: A Method of Case Hardening of Steel". Reference Module in Naterials Science and Materials Engineering: Comprehensive Materials Fishing, Vol. 2, 71106, 2017. 